\title{
INDUSTRY AND RESEARCH: NEW COLLABORATIVE PERSPECTIVES IN THE INDUSTRY 4.0 ERA
}

\author{
Zoltán FORGÓ, ${ }^{1}$ Levente BAKOS ${ }^{2}$ \\ ${ }^{1}$ Sapientia Hungarian University of Transylvania, Faculty of Technical and Human Sciences, Mechanical \\ Engineering Department, Târgu Mureș, Romania, zforgo@ms.sapientia.ro \\ ${ }^{2}$ Sapientia Hungarian University of Transylvania, Faculty of Technical and Human Sciences, Mechanical \\ Engineering Department, Târgu Mureș, Romania, bakos@ms.sapientia.ro
}

\begin{abstract}
The paper presents some challenges of developing DIHs (Digital Innovation Hubs) based on the Industry 4.0 principles in Transylvania (Romania). DIHs have proven to be successful as knowledge transfer centers especially in information technologies, but they are still a novelty in the field of manufacturing technologies and industrial engineering in many regions. The paper presents conceptual possibilities of developing a manufacturing technology based DIH in Romania, based on cooperation among local organizations.
\end{abstract}

Keywords: Digital Innovation Hub, Industry 4.0., $R \& D$ cooperation.

\section{Introduction}

With its centuries-old tradition the symbiotic relationship between academia and industry is far from new. Long before the first industrial revolution (in today's buzzword Industry 1.0), the manufacturing activities based on scientific achievements gained meaning; expertise and research-based innovation were provided by the academic environment for industrial organizations. At the same time, if we think of the economic stimulus effect of guilds, or the practice of apprenticeship, we can find examples in history well before the industrial revolutions of what we would call knowledge transfer today. But still, beyond the centuries - old antecedents, in the world of cyber - physical systems (CPS) and the era of the Internet of Things (IoT), the mutual interest cooperation between organizations in relation to manufacturing processes is still mostly an unsolved challenge. On the other hand, the fierce market competition, new geopolitical interests, but sometimes just an instinctive and mutual desire to help, creates stimulus and solutions for new forms of cooperation, sometimes even among competitors. Concepts that have been unknown for a few years, such as the Cluster, Incubator House, Start-up firm and, more recently, the
Digital Innovation Hub, are innovations that have taken the wealth of possibilities to previously unimaginable dimensions. And still. If we look at the abundance of initiatives of recent years (which then disappear for the most part), we can see that- beside the few undoubted success stories-, the general recipe has not yet been given. This is especially true for industrial manufacturing systems, which are one of the main engines of the EU and the world economy. The multi-layered process of product development and the dynamically changing market environment requires an ecosystem where it is almost possible to operate without intensive cooperation. But at the same time we must acknowledge that patents and data security issues are special constraints in any cooperation. Thus, some innovative processes needed to increase competitiveness are not worthwhile, except within the walls of the company.

\section{Cooperative ecosystems}

As stated above, several links between research and development (R\&D) organizations and companies had existed so far. There was a common interest in these partnerships from the beginning. On the one hand, it was the hope of increasing the company's competitiveness, and supporting business-valuable research on the other. The 
R\&D organizations, by which we mean university research centers and public/corporate consortia, represent a carefully designed innovative potential whose benefits should not be ignored. In these partnerships, the knowledge transfer is established through organized collaboration. These collaborations are organized along common interests, enabling the transfer of skills, knowledge and technologies between a research organization and a company. Nowadays, there are several opportunities for a joint program, starting with a commissioned contract, to a common application for non-refundable funds. The strength of the Industry 4.0 era lies in the ability to generate, collect and process massive amounts of data, previously inconceivable for normal industrial environments. Within Industry 4.0 we are few steps away from the smart factory concept, an efficient intelligent productive system consisting of networked manufacturing facilities. Smart factories make use of the combination of physical and cyber-technologies and deeply integrate previously independent discrete systems making the involved technologies more complex and precise than they are now [1]. Thus, Industry 4.0 no longer presupposes a bilateral cooperation, but a complex system developed for efficient innovation, an ecosystem including different regional players: SMEs, large industries, start-ups, researchers, accelerators and investors. Their mission is to support companies in becoming more competitive by exploiting the benefits of the digital transformation [2].

In this ecosystem, special relationships can be built which create a broader knowledge-transfer framework available to all involved partners. Within the ecosystem, there is a room for creative outsourcing, resource reallocations, and last but not least, to save a significant amount of time. There are geopolitical interests, at regional, national, even at global level to increase the competitiveness of companies through innovative networks. These systems can contribute to a more sustainable, more environmentally friendly economy in which the results of research and development processes can be applied in a wider range. [3]

The challenge for the members of the ecosystem is how to explore the available data in order to design, manufacture, reuse and neutralize competitive products in a circular economy. Key players in the ecosystem's data flow should represent the research and development organizations, which, may create opportunities by their infrastructure.
The functioning of the developed ecosystem is undoubtedly helped by the presence of innovation supply organizations (R\&D organizations, start-up companies, competence centers, NGOs and clusters), innovation demand organizations (large companies, small and medium-sized enterprises, start-up companies) and also innovation facilitator organizations (municipalities, incubator houses, investment funds, consulting companies, and Information Centers / Hubs).

Even though the goal is to build a network, there is a need for an orchestrator / coordinator to help build relationships, to match the supply and demand of innovation. Being in the middle of the Industry 4.0 era, mostly digital solutions have arisen. As a result, Digital Innovation Hubs have been set up and operating at regional level across Europe (there are more than 200 such coordinator units) [2].

The role of DIHs (Digital Innovation Hubs) in innovation processes can easily be demonstrated through the opportunities to connect to the phases of a product's life cycle [4]. The product development phases are milestones that are actually connection points with other ecosystem actors. DIH allows a partner to search for innovation partners at any stage during the product lifecycle development.

A DIH must be able to support innovation activities with infrastructure from time to time. Such is the case with the "LivingLab" concept, within which product prototypes and novel manufacturing processes are realized in a non-industrial environment [4].

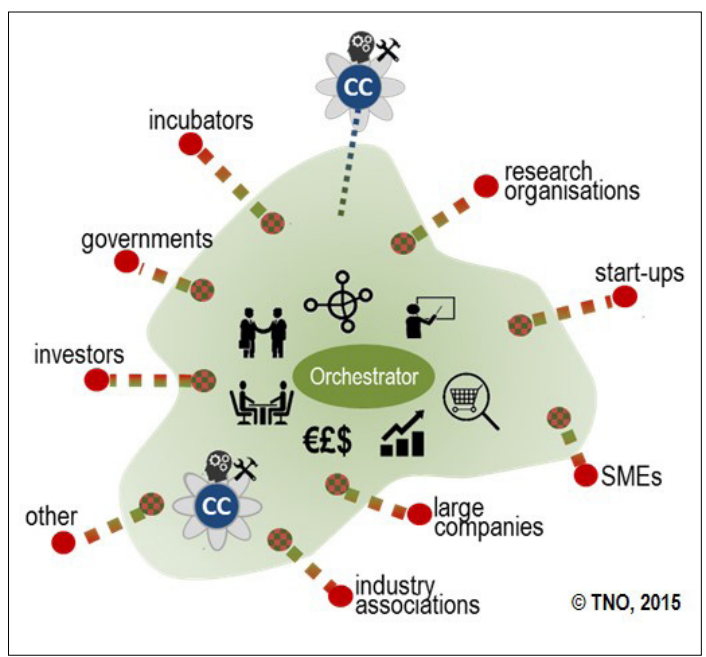

Figure 1. Regional multi-partner cooperation orchestrated by a DIH.[2] 


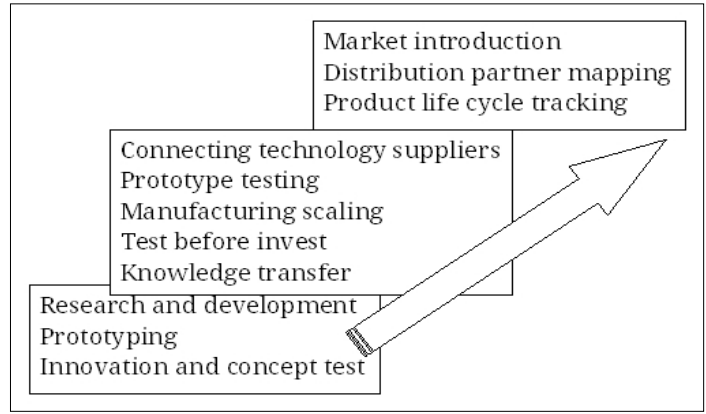

Figure 2. DIH services provided to support different stages of the product development.

In Table 1. we synthetically present innovation potential offered by the system for certain ecosystem actors. The table shows that the ecosystem is a win-win opportunity for both the academic environment, for-profit actors and for regional policy makers. While the latter sees the planned economic policy being implemented, researchers in scientific organizations are looking for answers to real challenges, and business owners can measure the success of the model in profits.

The table above highlights the benefits of creating a DIH, but we also need to mention some challenges, as well. Clearly, one of the biggest challenges for DIHs is to create an atmosphere of trust. Even with systematic steps and strategies, it is difficult to address and involve certain actors in the ecosystem. Overcoming resistance is only possible if the stated goals are understandable, the actors feel safe with their data and the results appear relatively quickly. Manufacturing, as our field of interest, being a for-profit activity defines clear performance indicators for all participants, despite the fact that this set of criteria is foreign to some DIH actors. Profit is not a priority for government participants, persons involved from NGOs or academics, but it is almost the only important aspect for businesses. This cognitive dissonance and goal conflict can easily be a major cause of failure, similar to the failure of previous similar types of initiative. Most of the conflicts originate because of the lack of proper communication. Industry 4.0 is making a qualitative leap in this field. Actors can communicate disproportionately better with each other based on cloud technology, we are in the Big Data era when previously unimaginable large data sets than can be handled, and IoT allows almost unlimited device interconnection [5]. The communication among ecosystem actors is already a simultane-
Table 1. Advantages for DIH partners

\begin{tabular}{|c|c|}
\hline DIH partner & Benefits \\
\hline $\begin{array}{l}\text { Firms } \\
\text { Large companies, } \\
\text { SMEs, Start-ups, } \\
\text { Investment } \\
\text { Funds }\end{array}$ & $\begin{array}{l}\text { Profit } \\
\text { Competitiveness } \\
\text { Innovative products } \\
\text { Smart factory, } \\
\text { CSR }\end{array}$ \\
\hline $\begin{array}{l}\text { R\&D Org } \\
\text { Research Centres } \\
\text { DIH, } \\
\text { Start-up organizations }\end{array}$ & $\begin{array}{l}\text { Real challenges } \\
\text { Real data } \\
\text { Industrial scale testing } \\
\text { Industry financing }\end{array}$ \\
\hline $\begin{array}{l}\text { Gov. Org. } \\
\text { Local Government } \\
\text { Regional Government } \\
\text { Regional Development } \\
\text { Agencies } \\
\text { State Institutions } \\
\text { National Government } \\
\text { EU institutions }\end{array}$ & $\begin{array}{l}\text { Life standard improve- } \\
\text { ment } \\
\text { Efficient resource alloca- } \\
\text { tion \& financing } \\
\text { New jobs } \\
\text { Political benefits }\end{array}$ \\
\hline
\end{tabular}

ous multi-partner instant communication, which in many cases makes possible to have decisions without human intervention. The ecosystem can take control of production processes to another level. For example, in the immediately pre-production phase, if a DIH operator makes a change to a product specification under its responsibility, the system will not only automatically modify the data in the partner databases without human intervention, within certain limits, but will also initiate internal actions.

\section{A Transylvanian local initiative}

It could be a definition of industrial revolutions that the knowledge they develop is exploding throughout the world, and even the less developed regions or organizations are benefiting from its scientific and technical achievements. Just as the spread of the steam engine, as an achievement of the first industrial revolution, changed the lives of the settlements of the most hidden regions of the world, so will it happen, probably at a disproportionately higher speed, in the case of the fourth industrial revolution. In fact, our goal is to make solutions based on Industry 4.0 principles available in the immediate region, drawing on a few months, often up to a few weeks of international practice, and to bond the participating organizations into a functioning ecosystem [6], [7]. We already possess the significant part of the partnerships required for this very ambitious goal. The arising DIH has several particularities, in addition to the fact that it is a novelty in the region. Among these particularities we mention 
the fact that the region in which it is located is attractive because of the challenges it offers. It is located in Eastern Europe, the region has a welldeveloped IT infrastructure with broadband services and there are a large number of IT specialists and firms available. The focus of our DIH is on the manufacturing industry. The region has a high density of manufacturing facilities from chemical and pharmaceutical to automotive industries. Still, the overall development status of the region is below the EU average.

The initiators are researchers from the Faculty of Sapientia Hungarian University of Transylvania, they have significant contacts in all major DIH participating segments (industry, education, politics, NGOs, clusters and the international DIH network). In principle, the conditions are in place for the operation of a local Digital Innovation Center. The role of the DIH would be to bring together the actors that are essential for the digital development of the area. The efficient functioning of an ecosystem is affected by a number of factors. The first important success factor is the clear formulation of the role of the DIH and to handle all of the objections itemized by potential stakeholders. Any actor or partner should find its place in the system and find the forms of cooperation that are beneficial to it. We plan to provide important support for this by presenting tailored best practices or by publishing case studies that reveal the synergistic nature of this type of networking. We are aware that it is impossible for a regional level network to provide an answer to all the digital innovation challenges that may arise at local level. To overcome this fact, it is necessary to actively participate in the European Network of Digital Innovation Centers. This way it is possible to take the advantage of the collective know-how available across Europe. Among the first results of our DIH, which is currently in the planning phase, may present the first established contacts with some Romanian DIHs and the possibility of integration into their network through partnership contracts. At the local level, a group of work-packages has been formulated that are innovative not only in the region, but also, to some extent, in all Eastern Europe. These features allow on the one hand a stand-alone operation, and on the other, a seamless integration into the existing DIH network.

In the current state, strategies within the different work packages are currently being harmonized. In order to coordinate the work with different DIH actors, in each work package must be at least one person to coordinate specific activities within the work package, having as task to bring together the innovation supply and demand. Once the two sides meet, the primary conditions for successful knowledge transfers are met. But this might not be a sufficient condition for knowhow transfer.

The created work packages are based on the MADE model. The MADE acronym comes from Manufacturing Academy of Denmark - a Danish national innovation and research platform designed to support the manufacturing industry in Denmark and to facilitate the development of innovative world-class manufacturing solutions. We kept their work package structure, but the content and description of services are based on our local industrial particularities. The work packages are illustrated in Figure 3.

Education and training activities are equally important, and not only within a work packages, but also in a cross-cutting way. The introduction of innovative digital technologies in companies presumes training, education, an upgrade of the skills of human resources. New technologies can be effective only if the human operators provide proper settings and operation. For us, as a new $\mathrm{DIH}$, during training and educational processes, a major challenge will be to explain the role of knowledge transfer centers and to design a selftailored, customized mechanism for involving companies At the same time, we experience some difficulties in carrying out some already tested best practices due to some language and cultural

\begin{tabular}{|c|c|}
\hline & $\begin{array}{l}\text { Work Package } 1 \\
\text { Digital Design, Modelling }\end{array}$ \\
\hline & $\begin{array}{l}\text { Work Package } 2 \\
\text { Smart Products }\end{array}$ \\
\hline & $\begin{array}{l}\text { Work Package } 3 \\
\text { Digital Manufacturing Processes }\end{array}$ \\
\hline & $\begin{array}{l}\text { Work Package } 4 \\
\text { Intelligent Supply Chains }\end{array}$ \\
\hline & $\begin{array}{l}\text { Work Package } 5 \\
\text { Smart Factories }\end{array}$ \\
\hline ? & $\begin{array}{l}\text { Work Package } 6 \\
\text { Digital Assistance Tools }\end{array}$ \\
\hline & $\begin{array}{l}\text { Work Package } 7 \\
\text { Organizing Digital Production }\end{array}$ \\
\hline$q^{\sigma o g}$ & $\begin{array}{l}\text { Work Package } 8 \\
\text { Automation with Robots }\end{array}$ \\
\hline 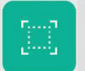 & $\begin{array}{l}\text { Work Package } 9 \\
\text { Sensor Technology and Production Data }\end{array}$ \\
\hline
\end{tabular}

Figure 3. Work packages [8]. 
constraints. Many skillful technical experts have a stiffened attitude to testing new technologies and have difficulties comprehending novel ideas in foreign languages. Last but not least, a key success factor for us will be the measure of how we might be active in the European Digital Innovation Hub Network. We are confident, that our ecosystem will contribute to the development of symbiotic relationships among local partners, by realizing and raising awareness of common interests. These include:

- increasing the competitiveness of companies

- support for business-valuable research

- transfer of skills, knowledge, technologies

- regional development.

\section{Conclusions}

Essentially, DIHs are not representing a revolutionary new idea, similar attempts between academia and industry look back on tradition. The new perspective in the context of Industry 4.0 is that partners can make it disproportionately easier to communicate with each other, handle larger data sets with previously unimaginable magnitudes, and have the ability to connect almost unlimited devices. The ecosystem is a win-win opportunity, as policy makers can see the planned economic policies being implemented, researchers can look for answers to real challenges, and businesses can measure the success of the developed theoretical models in terms of profit. Novel perspectives on collaboration between industry and research are open to all. As an example, we presented the first steps of a Transylvanian local initiative, namely a DIH coined by researchers from the Faculty of Sapientia University from Târgu Mureş, to create a region-level ecosystem. A significant part of the partnerships required for this ambitious goal is already given, and also we perceive a favorable industrial and political circumstance for the creation of a DIH focused on the manufacturing industry. The arising DIH has several particularities, in addition to the fact that it is a novelty in the region. Among these particularities we have mentioned the fact that the region in which it is located is attractive because of the challenges it offers. The DIH might create a testbed location for good practice initiatives. Currently, among the first results of the DIH in the planning phase, we mention the development of a specific work package group and the definition of the foundations of the training activity. In present, with more than 30 current partners, the operating rules of the DIH are instituted. At this moment, the main goal is to understand and to make the role of a DIH understood as an orchestrator of knowledge transfer. We are developing customized collaboration mechanisms for knowhow to know-how, mostly with mature DIHs from the EDIH network. Building strong and lasting partnerships with all involved stakeholders and each potential partner is a time-consuming and specialized task. The promotion of the project has also started, open calls for partnerships are launched. This article is a part of these initiatives.

\section{References}

[1] Chen, B. et al.: Smart Factory of Industry 4.0: Key Technologies, Application Case and Challenges, IEEE Access. Key Technologies for Smart Factory of Industry 4.0, 6. (2018) 6505-6519.

[2] European Commission, Digital Innovation Hubs - Smart Specialisation Platform (accesed on: December 3, 2020.)

https://s3platform.jrc.ec.europa.eu/digital-innovation-hubs-tool

[3] Ustundag A., Cevikcan E.: Industry 4.0: Managing The Digital Transformation. Springer International Publishing, 2018. https://doi.org/10.1007/978-3-319-57870-5

[4] Pucihar A., Zajc I., Sernec R., Lenart G.: Living Lab as an Ecosystem for Development, Demonstration and Assessment of Autonomous Mobility Solutions. Sustainability, 11/15. (2019) 4095. https://doi.org/10.3390/su11154095

[5] Wang S., Wan J., Zhand D., Li D., Zhang C.: Towards Smart Factory for Industry 4.0: A Self-organized Multi-agent System with Big Data Based Feedback and Coordination. Computer Networks, 101/1. (2016) 158-168.

https://doi.org/10.1016/j.comnet.2015.12.017

[6] European Commission, European Digital Innovation Hubs, 2020. (accesed on: December 3, 2020.) https://ec.europa.eu/digital-single-market/en/ digital-innovation-hubs

[7] AI DIH networks. AI Digital Innovation Hubs Network, 2020. (accesed on: December 3, 2020.) https://ai-dih-network.eu

[8] MADE - Manufacturing Academy of Danemark, 2020. (accesed on: December 3, 2020.) https://made.dk 